\title{
CLE peptide signaling during plant development
}

\author{
Guodong Wang • Martijn Fiers
}

Received: 19 November 2009 / Accepted: 20 November 2009/Published online: 17 December 2009

(C) The Author(s) 2009. This article is published with open access at Springerlink.com

\begin{abstract}
Peptide signaling in plants is a rapid developing area of research which focuses on so called peptide hormones. These signaling molecules are utilized for inter-cellular communication in different developmental processes, beside the usage of the more well-known phytohormones. Probably the best studied peptide ligands in plants are the CLAVATA3 (CLV3)/ENDOSPERM SURROUNDING REGION (ESR)related (CLE) proteins. This family of signaling polypeptides is comprised of 32 members in Arabidopsis and, with the exception of the presence of related proteins in some parasitic worms, is restricted to the plant kingdom. CLV3 is one of the founding CLE genes and is involved in stem cell niche maintenance in apical meristems during plant development. While the CLV signaling pathway is well characterized with the identification of three receptors and a stem-cellpromoting transcription factor as target, the functioning of other family members is not or poorly understood. The recent discoveries of a new type of receptor involved in CLV signaling and a functional pathway for CLE40 in root development mark the rapid progress that is made in the area of CLE peptide signaling. This review gives an overview how CLE peptides are used as signaling molecules, and how they are involved in cell-to-cell communication in concert
\end{abstract}

M. Fiers $(\bowtie)$

Plant Research International, Bioscience,

P.O. Box 16, 6700 AA Wageningen, The Netherlands

e-mail: Martijn.Fiers@wur.nl

G. Wang $\cdot$ M. Fiers

Centre for Biosystems Genomics (CBSG),

P.O. Box 16, 6700 AA Wageningen, The Netherlands

G. Wang

Laboratory of Phytopathology, Wageningen University,

P.O. Box 8025, 6700 EE Wageningen, The Netherlands with different known and unknown receptors in a range of developmental processes during plant development.

Keywords Meristem development . CLE peptide - Ligand . Clavata

\begin{tabular}{ll}
\multicolumn{2}{l}{ Abbreviations } \\
AA & amino acids \\
CLE & CLV3/ESR \\
CLV & clavata \\
CRN & coryne \\
CZ & central zone \\
FEA & fasciated ear \\
FON & floral organ number \\
FOS & FON2 SPARE1 \\
LRR & leucine-rich repeat \\
ESR & endosperm surrounding region \\
RLP & receptor-like protein \\
PZ & peripheral zone \\
RLK & receptor-like kinase \\
SAM & shoot apical meristem \\
TD & THICK TASSEL DWARF \\
WUS & wuschel
\end{tabular}

\section{Introduction}

In multicellular organisms, cell-to-cell communication is essential for coordinating growth and differentiation of cells into new tissues and organs. Hormones have been known for a long time to act as signaling molecules in plants for mediating physiological responses. Beside hormones, secreted signaling peptides have also been shown to be involved in inter-cellular communication in plants. SYSTEMIN was the first functional 
peptide ligand isolated from plants and is involved in the wounding response. In the last decade, several peptide ligands have been discovered in plants that are involved in a broad range of developmental processes like cell division (PHYTOSULFOKINE), pollen-stigma interaction, and stem cell maintenance (CLAVATA3 (CLV3)). Based on these studies, small secreted peptide ligands, also called peptide hormones, have become an important family of signaling molecules in plant development.

A well-known family of peptide ligands is encoded by the $C L E$ gene family. One of the founding family members in Arabidopsis is CLV3, which was shown to be active as a secreted peptide ligand and has a function in stem cell communication. The maintenance of stem cells during plant development requires a delicate balance between cell growth and restriction of cell proliferation, enabling maintenance of a constant pool of stem cells. CLV3 is involved in this process as a mobile peptide ligand, used as a short-range signal in inter-cellular communication. CLV1 and CLV2 are known to be the receptors involved in perception of the CLV3 peptide and translocation of the signal into the cell. Both are part of large and diverse gene families in plants. More recently the receptor-like kinase CORYNE (CRN) was identified as a new type of receptor involved in CLV3/endosperm surrounding region (ESR)-related (CLE) signaling. The identification of a third type of receptor increases the number of possible receptor pairs for CLE-type ligand perception, and, in combination with the different CLE peptides, this results in an extensive signaling potential that can be exploited during the different phases of plant development.

CLE signaling in the shoot apical meristem of Arabidopsis

The shoot apical meristem (SAM) in plants provides the founder cells for the initiation of new organs and can be divided into various zones and layers. The central zone (CZ) in the middle of the meristem is responsible for meristem maintenance, with an upper stem cell cluster marked by $C L V 3$ expression that provides cells for leaf formation and stem growth, together with a lower cell cluster: the rib zone (Fig. 1). The slow-dividing multipotent stem cells are located in a micro-environment (niche) in the $\mathrm{CZ}$ of the SAM where new cells are formed for the peripheral zone (PZ), but also for its own replenishment. The stem cells maintain simultaneously two antagonistic events: cell propagation and cell differentiation. The descendants of the $\mathrm{CZ}$ cells move into the $\mathrm{PZ}$ where the organs are initiated, which are leaves during the vegetative phase of development and flowers in the generative phase. In addition to its division into zones, the SAM can also be separated into different cell layers. The L1 and L2 layers represent the tunica layers whereas L3 represents the internal layers or corpus (Fig. 1).

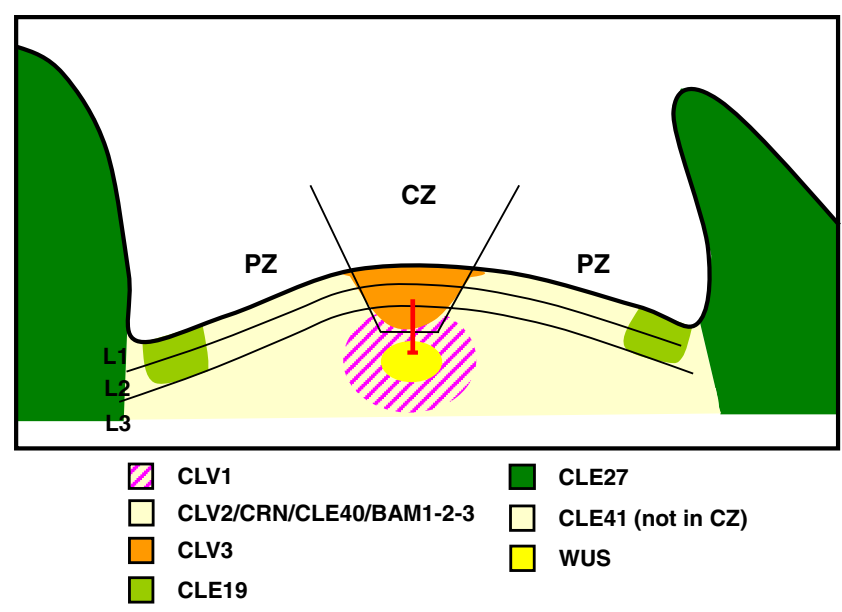

Fig. 1 Schematic representation of the shoot apical meristem expressed CLE genes and genes involved in the CLV pathway in the SAM. The central zone $(C Z)$ harbors the stem cells that are specified by $C L V 3$ expression and the organizing center is marked by $W U S$ expression and surrounded by $C L V 1$ expression. Next to the $C Z$ are the peripheral zones $(P Z)$ where organ primordia are initiated. CLE19 is specifically expressed in the periphery of the SAM where the new primordia will be formed and CLE27 is expressed in the developing organs. CLE41 is expressed in the SAM but excluded from the $\mathrm{CZ}$ whereas $C L E 40, C R N, C L V 2$, and the BAM receptors are expressed throughout the SAM. Expression data from CLE27 and CLE41 are based on the data from Yadav et al. (2009)

CLV3 is expressed in the stem cells of Arabidopsis meristems and encodes a secreted precursor protein, which is processed into a functional peptide hormone (Figs. 1 and 2; Kondo et al. 2006; Ohyama et al. 2009). CLV3 interacts with the underlying CLV1/CLV2 CRN/CLV2 receptor complexes to restrict the number of stem cells in the SAM (Fig. 1; Fletcher et al. 1999; Rojo et al. 2002). Where the stem cells are marked by $C L V 3$ expression, the underlying SAM organizing centre is marked by the expression of the stem cell-promoting WUSCHEL (WUS) gene (Fig. 1; Schoof et al. 2000). WUS, a homeobox transcription factor, provides a positive signal to maintain an undifferentiated state and functions antagonistically to the CLV pathway, which restricts stem cell development by negatively regulating WUS expression (Brand et al. 2000; Schoof et al. 2000). CLV3 in turn is positively regulated by WUS, creating a feedback regulatory loop between $C L V 3$ and $W U S$ that regulates the number of stem cells in the SAM. As such, clv1, clv2, and $\operatorname{clv} 3$ mutants have enlarged SAMs, while the wus mutation or $C L V 3$ over-expression results in differentiation of the stem cells and subsequently the termination of SAM development (Laux et al. 1996; Brand et al. 2000).

Induction of CLV3 expression in wild-type Arabidopsis results in a decrease of endogenous CLV3 and WUS expression already $3 \mathrm{~h}$ after induction (Müller et al. 2006). The balance between CLV3 and WUS expression is therefore essential for a proper specification of the $\mathrm{CZ}$ and 

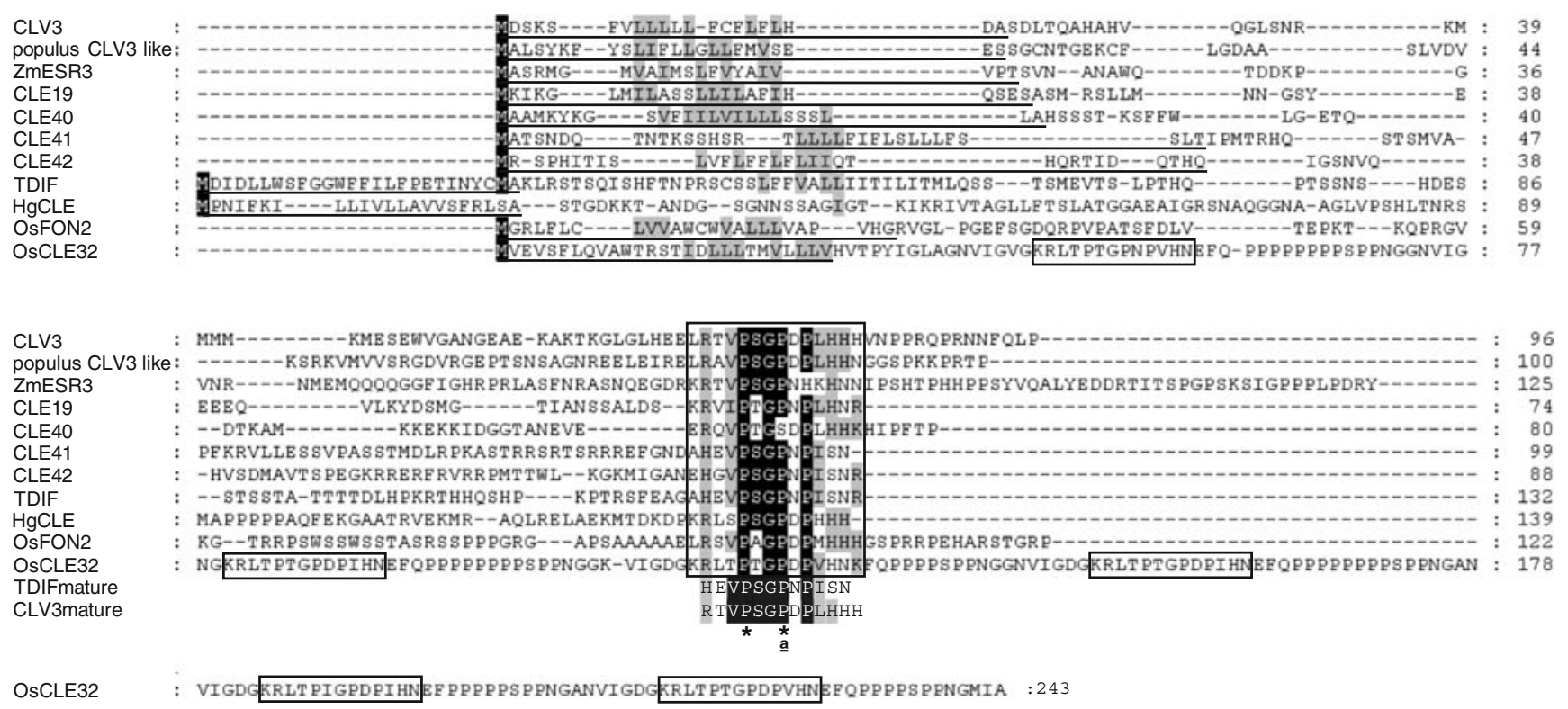

Fig. 2 Alignment of several CLE proteins from different plants and organisms including the mature peptide of CLV3 and TDIF. The signal sequences are underlined and the CLE box is framed. Note the four extra CLE domains in OsCLE32. MCLV3 and TDIF represent the

PZ domains; when this balance is disturbed it affects the rate of cell division accompanied by a respecification of cells from $\mathrm{CZ}$ to $\mathrm{PZ}$ or vice versa (Reddy and Meyerowitz 2005; Müller et al. 2006).

\section{CLV3/ESR gene family}

$C L V 3$ belongs to the CLV3/ESR (CLE) family of genes and is named after the first two founder genes, namely $C L V 3$ and endosperm surrounding region. ESR genes were first identified in maize as being expressed in the endosperm regions surrounding the embryo (Opsahl-Ferstad et al. 1997). All three ESR genes encode extracellular proteins with unknown function, but with a conserved CLE motif similar to CLV3 near their C-termini (Bonello et al. 2002; Cock and McCormick 2001). In Arabidopsis, the CLE family consists of 32 members of which the majority are transcribed in one or more tissues (Cock and McCormick 2001; Hobe et al. 2003; Sharma et al. 2003; Fiers et al. 2004; Strabala et al. 2006). All CLE genes share three characteristics with CLV3 and the ESR proteins: they encode a small protein $(<10 \mathrm{kD})$ with a putative secretion signal at their N-termini and contain a conserved 14-AA motif (CLE motif) at or near their C-termini (Fig. 2; Cock and McCormick 2001).

It is surprising to note that mutation of $C L E$ genes does not appear to result in visible mutant phenotypes except for the clv3 mutation, which results in an enlarged SAM and increased number of carpels inside the flowers (Clark et al. 1995). This could be due to redundancy of the CLE ligands, mature peptides, in which the first and second proline is hydroxylated (as indicated by asterisks) and in case of MCLV3 the second proline is arbinosylated (indicated by $a$ )

but is also caused in part by the fact that CLE genes are small, making it difficult to obtain a knock-out phenotype using a T-DNA insertion approach. Until now the only cle mutant with a phenotype, beside $\operatorname{clv} 3$ is the cle 40 mutant, which showed a very subtle root waving phenotype (Hobe et al. 2003). CLV3 is solely expressed in the CZ of the SAM while CLE4O is expressed in all tissues at low levels including the $C L V 3$ expression domain. Interestingly, when CLE40 is placed under the control of the regulatory elements of $C L V 3$, it can fully complement the $\operatorname{clv} 3$ mutant (Hobe et al. 2003). Nevertheless, despite the overlap in expression pattern and the fact that CLE40 can replace CLV3, endogenous CLE40 functions differently to CLV3, since the clv3/cle 40 double mutant exhibited only a $\operatorname{clv} 3$ phenotype and no enhancement of meristem defects was observed (Hobe et al. 2003). One possible explanation could be that the expression level of CLE4O is too low to replace CLV3 signaling (Yadav et al. 2009).

Domain mutation, deletion, or replacement strategies revealed the critical importance of the CLE motif (Fletcher et al. 1999; Fiers et al. 2006; Ni and Clark 2006). One point mutation in the CLE motif present in the clv3-1 and clv3-5 mutants is already sufficient to abolish CLV3 function (Fletcher et al. 1999). The region between the signal sequence and CLE motif can be removed or replaced by unrelated ERECTA sequences and the C-terminal sequence after the CLE motif can be deleted without interfering with the function of CLV3. However, the removal of the CLE motif abolished its function completely (Fiers et al. 2006; Ni and Clark 2006). 
Exchanging the CLE domain of CLV3 with those from other CLE proteins resulted in variable degrees of complementation in $\operatorname{clv} 3-1$ background, from almost complete complementation in the case of CLE1 and CLE6, to hardly any effect with CLE25 and CLE26 (Ni and Clark 2006). Taking an over-expression approach using 17 CLE genes from Arabidopsis resulted in termination of the SAM similar to CLV3 for 10 CLE genes, revealing functional similarity between the CLE ligands (Strabala et al. 2006). Because the CLE motif was the only commonly shared domain among CLE proteins and CLE proteins are secreted, synthetic peptides comprising the CLE motif were tested for their functionality. Experiments using in vitro applied peptides showed that the $\operatorname{clv} 3$ defect in the SAM could be restored with the use of different CLE peptides. Testing 26 CLE peptides, comprising all 32 CLE peptide sequences in Arabidopsis, resulted for 10 CLE peptides in a reduction of the SAM size as seen with the CLV3 peptide (CLV3p; Fiers et al. 2006; Kinoshita et al. 2007).

These peptide and domain swapping experiments revealed an interesting redundancy among the CLE family members, in which the receptors seem to be able to tolerate a certain degree of CLE sequence variants. Several CLEs are able to replace CLV3 in vitro or when placed under the CLV3 regulatory elements, but there is no evidence that this also occurs in planta. Since the secreted CLE molecules are not able to travel over long distances (Lenhard and Laux 2003), a biologically relevant redundancy requires an overlapping or adjacent expression pattern, and a sufficiently high expression level.

The quest for the mature CLV3 peptide was thought to come to an end with the identification of a functional CLV3 (MCLV3) peptide using callus over expressing CLV3. This MCLV3 peptide consists of 12 amino acids (AAs; RTVP ${ }^{\mathrm{h}} \mathrm{SP}^{\mathrm{h}} \mathrm{DPLHH}$ ) comprising the CLE motif, of which the first two prolines were modified to hydroxyproline (Kondo et al. 2006). More recently the CLV3 peptide was isolated from culture media derived from whole-plants of Arabidopsis over expressing CLV3. Interestingly, this isolated CLV3 peptide was composed of 13 AA comprising the CLE motif (RTVPh ${ }^{\mathrm{h} G P}{ }^{\mathrm{ha}} \mathrm{DPLHHH}$ ), in which the second hydroxyproline on position 7 was arabinosylated (Ohyama et al. 2009, Fig. 2). This arabinosylation was shown to be critical for the biological activity of CLV3 and CLE2 and the binding of CLV3 to the CLV1 receptor even at nano-molar concentrations (Ohyama et al. 2009).

Beside the identification of CLE peptides in Arabidopsis, a CLE-like peptide, tracheary element differentiation inhibitory factor (TDIF), was isolated from Zinnia Elegans mesophyll cell culture medium and identified as a suppressor of xylem development (Ito et al. 2006). This 12-AA CLE peptide (HEVP ${ }^{\mathrm{h}}$ SGP ${ }^{\mathrm{h}}$ NPISN), with two hydroxylated prolines, as seen for MCLV3, is identical to the CLE domain of CLE41/44. Three CLE peptides, CLE41, 42, and 44 containing two hydroxyproline residues, were shown to independently suppress tracheary element differentiation, but were unable to terminate development of the root apical meristem (Fig. 2; Ito et al. 2006). CLV3 and other CLE peptides involved in the suppression of stem cell development in root and shoot development are named A-type CLE peptides; this in contrast to the B-type CLE peptides, CLE41 and CLE44, in the case of Arabidopsis, which do not (Whitford et al. 2008). B-type CLE peptides suppress the differentiation of xylem cells from stem-cell-like procambial cells and promote cell division. Interestingly, a functional CLV3 peptide was able to promote xylem cell differentiation in a Zinnia cell culture revealing two counteracting pathways in vascular development, one that promotes and one that inhibits stem cell differentiation (Ito et al. 2006). The initial hypothesis that these two classes of peptides work antagonistically was shown to be too simple. CLE41 (a B-type CLE peptide) promoted the proliferation of vascular cells, but combining the A and B-type CLE peptides had a synergistic effect resulting in a massive proliferation of vascular cells which was shown to rely on auxin signaling (Whitford et al. 2008). The combination of A and B-type classes of peptides resulted in a disturbed ratio between cell division and cell differentiation revealing a complex crosstalk of different types of CLE peptides during vascular development.

There are no A-type peptides reported to be involved in vascular development, but noteworthy in this respect is one of the phenotypes observed after mis-expression of CLE19. This A-type CLE peptide caused, among other phenotypes, a failure in the connection of the xylem network (Fiers et al. 2004). CLE19 mis-expression seems to induce a differentiation into xylem cells resulting in vascular islands in the flower bud without a connection to the main stem. Interesting in this respect is the endogenous expression of CLE19 in root pericycle cells facing the protoxylem poles which points to a function in vascular development in roots (Fiers et al. 2004).

Is a CLV-like signaling pathway involved in root meristem maintenance?

There are several similarities between stem cell populations in the root and shoot meristem which raises the question as to whether similar stem-cell-maintaining pathways, particular the CLV pathway, are present both in shoot and root meristems? While endogenous $C L V 3$ is not expressed in roots, over-expression of $C L V 3$ does result, as in the SAM, in the consumption of the root meristematic cells. This phenotype is shared in vivo by several $C L E$ genes such as CLE40 and CLE19 upon over-expression (Hobe et al. 2003; Fiers et al. 2004; Casamitjana-Martinez et al. 2003; Strabala 
et al. 2006). Both these genes, like many other CLEs, are expressed during root development but their function is unknown (Fig. 3; Fiers et al. 2004; Hobe et al. 2003; Birnbaum et al. 2003). To find regulators in the CLE signaling machinery during root development a transgenic line that over-expresses CLE19, was used as basis for a mutagenesis approach (Casamitjana-Martinez et al. 2003). This resulted in the identification of two mutants involved in the CLE perception namely Suppressor Of LLP1 (sol1) and sol2 (Casamitjana-Martinez et al. 2003). The SOL1 locus was cloned and encodes a $\mathrm{Zn}^{2+}$ carboxypeptidase which is expressed throughout the plant and supposed to play a role in ligand processing (Casamitjana-Martinez et al. 2003). Remarkably, the soll mutant does not display any phenotype, beside the suppression of CLE19 overexpression, making it unlikely that SOL1 is generally involved in CLE processing (Casamitjana-Martinez et al. 2003). SOL2 was later identified as CRN, a membranebound receptor kinase lacking an extracellular domain (Müller et al. 2008; Miwa et al. 2008).

Several CLES were shown to cause a consumption of the root upon over-expression independent of their endogenous expression pattern; though the effect seems to correlate with a particular level of sequence similarity (Fiers et al. 2005; Strabala et al. 2006; Kinoshita et al. 2007). This termination of the root meristem can be mimicked by the exogenous application of synthetic CLE peptides comprising the CLE motif (Fiers et al. 2005; Ito et al. 2006). An in vitro root assay using CLE peptides revealed a mis-specification of the pericycle, endodermis, and cortex cell-layers in root development upon CLE treatment (Fiers et al. 2005). Also the cortical daughter cells were affected and increased in

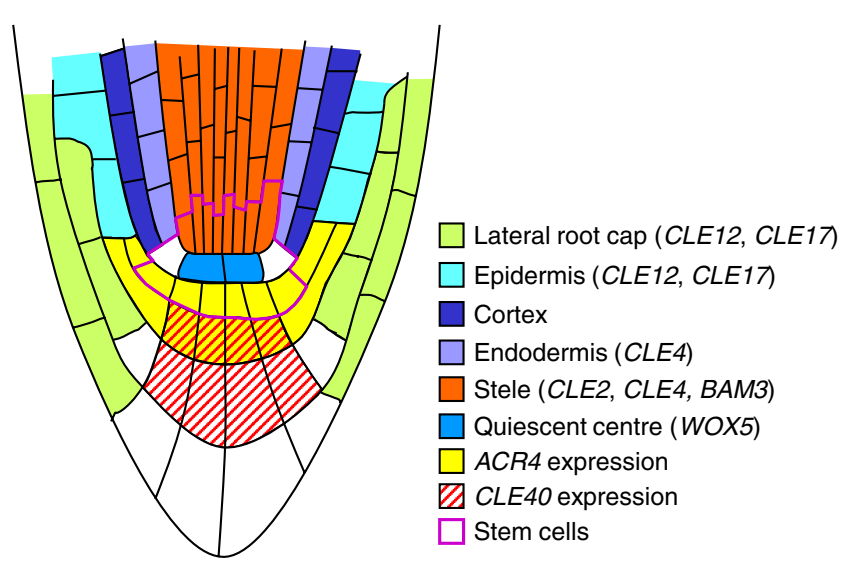

Fig. 3 Structure of the root with all CLE genes expressed in the meristematic area and any known receptors and targets of CLE signaling. The $B A M 3$ receptor is mainly expressed in the stele while $B A M 1$ and $B A M 2$ are expressed throughout the root. The expression data from CLE2, CLE4, CLE12, CLE17, and the BAM receptors are based on the data from Birnbaum et al. (2003), combining the expression of stage 1 and 2 in root development with a cutoff of 40 number, but lost their stem cell identity and obtained a cortex fate (Fiers et al. 2005). An excess of CLE protein seemed to interact with or block an unknown cell-identitymaintaining receptor complex in the roots. Direct evidence for a CLV pathway in roots comes from the fact that CLV receptors are involved in perception of the CLE signal. Two of these receptors, namely the CLV2 receptor-like protein and CRN were shown to be involved in the CLE signal perception, suggesting the presence of a CLV-like dependent signaling pathway in the root meristem (Fiers et al. 2005; Müller et al 2008). CLE-mis-expression effects seem to be mediated by CRN and CLV2 but except for this, the function of both proteins in normal root development remains unclear.

All of the above experiments rely on the over-expression of CLE genes or exogenous application of CLE peptides, mimicking mis-expression. Although informative, the results from these experiments do not necessarily reflect the endogenous function of the individual CLE peptides during root development. Many $C L E$ genes are expressed in the root but up till now their function remains elusive (Fig. 3; Birnbaum et al. 2003). Actually, the only CLE gene in root development with a mutant phenotype upon knock out is CLE40 (Hobe et al. 2003). CLE40 was shown to be expressed in the columella cells, and the mutant shows multiple layers of columella stem cells together with an enlarged WOX5 expression pattern (Stahl et al. 2009). WOX5 is a root-specific WUS-like homeobox transcription factor. The cle 40 mutant resembles the phenotype of the acr4 (ARABIDOPSIS CRINKLY4) mutant which encodes a membrane-localized receptor-like kinase (De Smet et al. 2008). In vitro application of the synthetic CLE40p or the related CLV3p, rescued the cle 40 mutants, but not the acr 4 mutants. Therefore, Stahl et al. (2009) proposed that CLE40 and ACR4 form a ligand-receptor pair that regulates WOX5 expression levels and controls the balance between proliferation and differentiation of distal root stem cells (Stahl et al. 2009).

This is the first example of a CLE peptide/receptor/ transcription factor signaling cascade that influences stem cell development in the root meristem. How other CLE peptides influence this process, and perhaps other types of stem cells in the root, from which the individual cell lineages originate, remains to be investigated.

\section{CLE genes in the plant kingdom}

CLE genes have been identified in a wide variety of plant species including both dicotyledons (Arabidopsis, tomato, and soybean), monocotyledons (rice and wheat), and even in the moss Physcomitrella (Oelkers et al. 2008). An interesting observation in the domain organization of CLE genes is the presence of a multi-CLE domain in some 
species, as seen in rice, Medicago, and Tritium (Oelkers et al. 2008; Cock and McCormick 2001). This multidomain organization is not observed in Arabidopsis and the significance of having multiple CLE domains in one protein, even up to six domains as seen in the case of CLE75 in rice, is not known but could be used to amplify or even diversify the CLE signal (Fig. 2; Oelkers et al. 2008).

Several studies have revealed the conservation of the CLV signaling pathway in monocotelydons as observed for rice and maize. An interesting difference in meristem maintenance was observed in rice where the regulation of stem cells in the vegetative stage and inflorescence/floral meristems during the generative stage of development seems to be uncoupled (Suzaki et al. 2008). Mutation of FLORAL ORGAN NUMBER 1 (FON1) or FON2 (also known as FON4) causes an enlargement of the floral meristems and an increase in the number of floral organs (Nagasawa et al. 1996; Suzaki et al. 2004, 2006; Chu et al. 2006). Where FON1 is the CLV1 orthologue in rice, FON2 is a small secreted protein containing a CLE domain which is very similar to Arabidopsis CLV3 (Fig. 2; Suzaki et al. 2006; Chu et al. 2006). FON2 was shown to signal via the FON1 receptor and is able to complement the clv3-1 mutant in Arabidopsis, revealing a CLV pathway involved in meristem maintenance in rice (Suzaki et al. 2006; Chu et al. 2006). The diversification of meristem maintenance between rice and Arabidopsis came with the observation that while fon 2 causes an enlargement of the floral meristem, vegetative meristems were not enlarged. Nevertheless, this observation is in disagreement with that of Chu et al. (2006) and Suzaki et al. (2006). The missing CLE signal came with the identification of FON2-LIKE CLE PROTEIN1 (FCP1) and FON2 SPARE1 (FOS1) which were shown to be involved in maintenance of the vegetative meristems (Suzaki et al. 2008). While FON2 signals via the FON1 receptor in floral meristems, both FCP1 and FOS1 use a different receptor to relay their signal. Taken together, these results show an uncoupling of the vegetative and inflorescence/floral meristem maintenance by diversification of the CLE signal and receptor (Suzaki et al. 2008). This is in contrast to Arabidopsis in which the stem cell maintenance of all meristems above ground is regulated by the CLV signaling machinery.

\section{CLE signaling in nematodes}

While CLE peptides are known to be involved in inhibiting or promoting cell differentiation in plant meristems, surprisingly this family of signaling peptides is not restricted to the plant kingdom (Mitchum et al. 2008). The first CLE gene that was identified outside the plant kingdom is $H g S Y V 46$, from the parasitic soybean cyst nematode Heterodera glycines (Wang et al. 2005; Olsen and Skriver 2003). This $H g C L E$ gene contains all the CLE characteristics namely a putative signal sequence at its $\mathrm{N}$ terminus and a 14 AA CLE domain near its C terminus (Fig. 2). The functionality of this nematode CLE was shown upon expression in Arabidopsis, by complementation of the clv3-1 mutant and mis-expression in wildtype causing a termination of the shoot and root meristems similar to mis-expressed CLV3 (Wang et al. 2005).

$\mathrm{HgSYV} 46$ was shown to be specifically expressed within the dorsal esophageal gland cell (Wang et al. 2005; Olsen and Skriver 2003). Interestingly, from the dorsal esophageal gland cell of a potato cyst nematode five different $C L E$ genes were identified. Four of these genes contained multiple CLE motifs as has also been seen for rice, Medicago, and Tritium multidomain CLE genes ( $\mathrm{Lu}$ et al. 2009; Oelkers et al. 2008).

The presence of these CLE genes in parasitic nematodes raises the question as to whether these CLE peptides are used by these worms to mimic plant signals. In this regard, the esophageal gland cells of nematodes actively synthesizes secretions which are injected through the stylet (hollow oral feeding spear) into cells to change the cell identity into specific feeding cells (Davis and Mitchum 2005). The hypothesized ligand mimicry of CLE signaling peptides by nematodes is a beautiful example of adaptation by a worm making use of plant endogenous signals for reprogramming of cell identity for its own benefit.

\section{Receptors that function in meristem maintenance}

Insight into the maintenance of stem cells in the SAM has revealed two receptor complexes, which probably act independently of each other (Müller et al. 2008; Andrea and Rüdiger 2009; Butenko et al. 2009). The CLV1 gene encodes a leucine-rich repeat-receptor-like protein (LRRRLP) with 23 consecutive LRRs, a transmembrane domain and a functional cytoplasmic kinase domain (Clark et al. 1997). CLV3 and CLV1 were demonstrated as a ligandreceptor pair in stem cell maintenance by showing that CLV3 binds to the extracellular LRR domain of CLV1 (Ogawa et al. 2008). CLV2 is an LRR-RLP lacking a cytoplasmic kinase domain (Jeong et al. 1999), which acts with CRN in a parallel pathway to transmit the CLV3 signal (Müller et al. 2008). The $\mathrm{crn} / \mathrm{sol} 2$ mutant, like the $c l v$ mutants, shows an enlarged SAM and is defective in floral organ development (Casamitjana-Martinez et al. 2003; Miwa et al. 2008; Müller et al. 2008). This suggests that CRN/SOL2 is implicated in the repression of WUS signaling. However, whereas the clvl crn double mutant has an additive effect on carpel number, the $c l v 2 \mathrm{crn}$ mutant has carpel numbers similar to each single mutant, implying that CRN and CLV2 act together, but independently of CLV1 (Müller et al. 2008). CRN encodes a membrane- 
bound receptor kinase containing a short non-LRR extracellular domain and a cytoplasmic kinase domain (Miwa et al. 2008; Müller et al. 2008). Thus, CRN/SOL2 has a kinase domain which might create a fully functional transmembrane receptor kinase together with CLV2 through dimerization by the transmembrane domain regions (Müller et al. 2008), while the extracellular LRR domain of CLV2 might interact with a putative ligand such as CLV3. However, whether CLV3 peptide can directly bind to the extracellular domain of CLV2 remains to be proven. Nevertheless, the CLV3 signal is probably transduced through two separate receptor complexes, one comprising CLV1 and the other one comprising CRN and CLV2 (Müller et al. 2008; Andrea and Rüdiger 2009; Butenko et al. 2009).

Unlike CLV1 that has a restricted expression domain, $C L V 2$ and $C R N / S O L 2$ are widely expressed in many plant tissues (Jeong et al. 1999; Miwa et al. 2008; Müller et al. 2008). Specifically, the roots of $c l v 2$ and $\mathrm{crn} / \mathrm{sol} 2$ mutants are unaffected upon CLE peptide treatment, suggesting that CRN, like CLV2, is involved in transmitting CLE signals in root meristems (Fiers et al. 2005; Miwa et al. 2008; Müller et al. 2008). While both CLV2 and CRN/SOL2 are expressed in root apical meristems, no alteration on root development was observed in $\mathrm{crn}$ and/or $\mathrm{clv} 2$ mutant plants (Müller et al. 2008; Wang and Fiers, unpublished data; Kayes and Clark 1998; Miwa et al. 2008).

Three CLV1-related receptor-like proteins BAM1-3 (BARELY ANY MERISTEM1-3) have been found to counteract CLV1 in stem cell maintenance (DeYoung et al. 2006). As such, the mutants of these receptors exhibit partial loss of stem cell identity within the shoot and flower meristem (DeYoung et al. 2006). Conversely, weak phenotypes of $c l v 1$ null alleles were enhanced by the bam mutations, resulting in enlarged SAM formation (DeYoung and Clark 2008). The differences of CLV1 and BAM receptors are largely determined by differences in their transcriptional patterns, with BAMs being expressed in the periphery zone of the meristem and therefore outside of the CLV1 expression domain (DeYoung et al. 2006; DeYoung and Clark 2008). Therefore, it is proposed that the BAM receptors function to sequester CLE ligands produced in the periphery zone. As such, BAM receptors bring into the CLV1 signaling pathway the necessary control over the delicate balance required for stem cell maintenance (DeYoung and Clark 2008; Butenko et al. 2009).

ER (ERECTA), which encodes an LRR-RLK, is a versatile modulator of responses to environmental stimuli and a multiple regulator of developmental and physiological processes (van Zanten et al. 2009). The loss-of-function of ER results in a compact inflorescence, suggesting a role in meristem regulation (Torii et al. 1996; Yokoyama et al. 1998). ER is predominantly expressed in the SAM and organ primordia in a cell-specific and developmentally regulated manner (Yokoyama et al. 1998). In addition, it has been shown that transfer of clvl alleles into Ler strongly enhanced the $c l v 1$ phenotype (Diévart et al. 2003), suggesting an overlap in function between CLV and ER in SAM regulation.

A screening of LRR-RLK genes T-DNA insertion mutant plants for insensitivity to TDIF led to the identification of the putative TDIF receptor TDR (Hirakawa et al. 2008). TDR is identical to PHLOEM INTERCALATED WITH XYLEM (PXY), which maintains cell polarity required for the orientation of cell division during vascular development together with two closely related RLKs, PXL1 (PXY-LIKE1) and PXL2 (Fisher and Turner 2007). Furthermore, TDIF binds in vitro specifically to TDR/ PXY, suggesting that the fate of vascular stem cells may also be controlled by a similar CLV receptor system as in the SAM (Hirakawa et al. 2008).

Like the CLE ligands, CLV-like receptor signaling is also conserved in the angiosperms

There are several similarities between meristem maintenance between mono- and dicotyledonous plants. For example, the CLV1 orthologue in rice, FON1, causes enlarged floral meristems when mutated, resulting in an increased number of floral organs similar to $c l v 1$ (Suzaki et al. 2004). Beside FON1, a functional rice CLV2 orthologue remains to be determined, although it has been suggested that CLV2 is functionally conserved in vascular plants (Miwa et al. 2009).

In maize, the fea2 (fasciated ear2) mutant has a phenotype that resembles the meristem enlargement found in Arabidopsis clv mutants, although its role differs in some aspects (Taguchi-Shiobara et al. 2001). FEA2 encodes an LRR-RLP that has many structural features in common with CLV2 (Taguchi-Shiobara et al. 2001). The presence of FEA2 as a CLV2 orthologue suggests a conserved CLV pathway in maize. In line with this, maize THICK TASSEL DWARF1 (TD1) most likely encodes a functional orthologue of Arabidopsis CLV1 (Bommert et al. 2005). A mutation in TD1 leads to a dramatic fasciation of the ear tip, resulting in an enlarged inflorescence meristem. In Arabidopsis, the CLV1 and CLV2 proteins are proposed to form a heterodimeric receptor complex as supported by genetic analyses (Jeong et al. 1999). The resemblance between phenotypes of $t d 1$ and $f e a 2$, and the similarity of their protein features with CLV1 and CLV2, respectively, suggests that TD1 and FEA2 may also occur as heterodimers in a receptor complex. However, the genetic analyses on $t d l$ fea 2 double mutants suggests that $t d l$ and fea 2 do not likely function in a single pathway as described for CLV1 and CLV2 (Bommert et al. 2005). Together with the data from rice, these results suggest that the CLV 
signaling pathway which regulates meristem maintenance is basically conserved, although there are some diversifications between mono- and dicotyledenous plants, as has also been seen with the $C L E$ genes.

RLKs and the RLP family

In Arabidopsis, about 600 RLKs have been identified, representing $2 \%$ of the organism's protein-coding genes (Shiu and Bleecker 2001). RLKs participate in a range of diverse processes, including disease resistance, hormone, or peptide perception and regulation of many developmental processes, such as meristem development, stem elongation, pollination, and defense (Afzal et al. 2008; De Smet et al. 2009; Table 1). However, for only a few of the Arabidopsis RLKs has a function has been assigned (Afzal et al. 2008; De Smet et al. 2009; Table 1). Fifty-seven and ninety RLPs that are similar to CLV2 were identified by in silico analyses in the Arabidopsis and rice genome, respectively (Fritz-Laylin et al. 2005; Wang et al. 2008). Like the CLE genes, the function of only a very few of these RLPs functions have been ascribed (Wang et al. 2008).

A recurrent theme in RLK and RLP signaling is the role of homo- or heterodimerization in the formation of an active receptor complex. Although heterodimerization of an RLP with an RLK seems a crucial step for receptor-based signaling, only a few examples of dimerization have been confirmed so far (Butenko et al. 2009; De Smet et al. 2009). It has been proposed that one RLK recruits one RLP for the formation of a functional receptor complex (Stein et al. 1991; Shpak et al. 2005).

The large RLK and RLP family results in theory in a huge number of putative receptor complexes of which the CLE peptides are putative ligands. For the moment this remains speculative and it will be of great interest to identify more receptor complexes in future studies.

Table 1 Receptor-like kinases and receptor-like proteins with a function in meristem maintenance

\begin{tabular}{|c|c|c|c|c|c|}
\hline Gene & Organism & Function & Family & $\begin{array}{l}\text { Putative } \\
\text { ligand(s) }\end{array}$ & References \\
\hline$C L V 1$ & Arabidopsis & Meristem maintenance & LRR-RLK XI & CLV3/CLEs & $\begin{array}{l}\text { Clark et al. 1995, 1997; } \\
\text { Trotochaud et al. 1999; } \\
\text { Ogawa et al. } 2008\end{array}$ \\
\hline CLV2 & Arabidopsis & $\begin{array}{l}\text { Meristem maintenance } \\
\text { and organ development }\end{array}$ & LRR-RLP & CLV3/CLEs? & \\
\hline$B A M 1$ & Arabidopsis & $\begin{array}{l}\text { Meristem, gametophyte, ovule, } \\
\text { and vascular development }\end{array}$ & LRR-RLK XI & CLEs? & $\begin{array}{l}\text { DeYoung et al. 2006; } \\
\text { Hord et al. } 2006\end{array}$ \\
\hline$B A M 2$ & Arabidopsis & $\begin{array}{l}\text { Meristem, gametophyte, ovule, } \\
\text { and vascular development }\end{array}$ & LRR-RLK XI & CLEs? & $\begin{array}{l}\text { DeYoung et al. 2006; } \\
\text { Hord et al. } 2006\end{array}$ \\
\hline$B A M 3$ & Arabidopsis & $\begin{array}{l}\text { Meristem, gametophyte, ovule, } \\
\text { and vascular development }\end{array}$ & LRR-RLK XI & CLEs? & $\begin{array}{l}\text { DeYoung et al. 2006; } \\
\text { Hord et al. } 2006\end{array}$ \\
\hline ERECTA & Arabidopsis & $\begin{array}{l}\text { Meristem/organ/stomatal } \\
\text { development/resistance to } \\
\text { Ralstonia solanacearum }\end{array}$ & LRR-RLK XIII & EPF1? & $\begin{array}{l}\text { Torii et al. 1996; } \\
\text { Groß-Hardt and Laux } 2003 \\
\text { Shpak et al. 2005; } \\
\text { Shpak et al. 2005; } \\
\text { Hara et al. } 2007\end{array}$ \\
\hline$A C R 4$ & Arabidopsis & Cell layer organization & LRR-RLK CR4L & CLE40 & $\begin{array}{l}\text { Gifford et al. 2005; } \\
\text { Watanabe et al. 2004; } \\
\text { De Smet et al. 2008; } \\
\text { Stahl et al. } 2009\end{array}$ \\
\hline$S C M$ & Arabidopsis & Positional development in root & LRR-RLK V & $?$ & Kwak et al. 2005 \\
\hline$R P K 1$ & Arabidopsis & $\begin{array}{l}\text { ABA signaling/embryonic and } \\
\text { postembryonic development; } \\
\text { positional development in root }\end{array}$ & LRR-RLK UC & $?$ & $\begin{array}{l}\text { Osakabe et al. 2005; } \\
\text { Nodine et al. 2007; } \\
\text { Nodine and Tax } 2008\end{array}$ \\
\hline RPK2/Toad 2 & Arabidopsis & $\begin{array}{l}\text { Anther, embryonic, and postembryonic } \\
\text { development; positional development } \\
\text { in root }\end{array}$ & LRR-RLK UC & $?$ & $\begin{array}{l}\text { Mizuno et al. 2007; } \\
\text { Nodine et al. 2007; } \\
\text { Nodine and Tax } 2008\end{array}$ \\
\hline$P X Y / T D R$ & Arabidopsis & Vascular stem cells maintenance & LRR-RLK XI & CLE41/CLE44 & $\begin{array}{l}\text { Fisher and Turner 2007; } \\
\text { Hirakawa et al. } 2008\end{array}$ \\
\hline FEA2 & Maize & Meristem and vegetative development & LRR-RLP & $?$ & Taguchi-Shiobara et al. 2001 \\
\hline$T D 1$ & Maize & Meristem and vegetative development & LRR-RLK XI & $?$ & Bommert et al. 2005 \\
\hline FON1 & Rice & Floral meristem maintenance & LRR-RLK XI & FON2? & Suzaki et al. 2004 \\
\hline
\end{tabular}




\section{Conclusions and perspectives}

In the last years, research on CLE signaling has been boosted through several interesting discoveries on the identification of the active peptide, together with the functioning and expression of several CLE genes. However, despite all of these new findings a recurring issue remains the lack of phenotypes after mutagenesis of individual CLE genes. A possible explanation might be that knock-out phenotypes are subtle, or are only visible under certain environmental conditions. Another aspect to take into consideration is the possibility of widespread redundancy among the CLE genes. CLE specification seems to rely, at least in part, on their expression pattern and level. This is demonstrated by the fact that upon misexpression, multiple CLE genes can activate (or repress) similar pathways. The idea that CLE peptides can be used as short-range signaling molecules fits with the observation that CLE peptides seem to act locally. However, there is no evidence that these peptides can travel over longer distances like phytohormones. At any rate, the relationship between CLE signaling and the phytohormones is poorly understood: there seems to be no connection between CLE peptide and hormone signaling, but this is unlikely and awaits further investigation.

The LRR receptors used to perceive the CLE signal belong to a large family of receptors in plants potentially resulting in numerous CLE-receptor combinations. These combinations enable specific functions and responses for each CLE-receptor interaction. Interesting in this respect are the BAM receptors, whose mutants show a reduction in the size of the shoot meristem, this in contrast to the $c l v$ mutants. Though a CLE ligand for the BAM receptors has not yet been found, it is an intriguing hypothesis that CLE peptides, beside their involvement in the suppression of stem cell development as shown for CLV3, may also involved in the promotion of stem cell development in the SAM using the BAM receptors to relay their signal.

The CLV pathway is an example of a pathway in plants that is relatively well understood, but almost entirely based on genetic information. The identification of the endogenous CLV3 peptide ligand in combination with an in vitro CLE peptide approach opens new avenues for the isolation and characterization of functional ligand-receptors complexes. It has also become more and more evident that CLE peptides are involved in many aspects of plant development. The identification of $C L E$ genes in pathways other than meristem maintenance provides new insights into CLE signaling and encourages considering CLE peptide as ligands in many other pathways. Since CLE peptides have proven to be very instrumental in cell-to-cell communication in plants, we can expect many new exiting findings in the future.
Acknowledgements We thank Dr. Richard Immink and Prof. Gerco Angenent for revising this review. Work in the author's laboratory was supported by the Netherlands Proteomics Centre (NPC) and the Centre for BioSystems Genomics (CBSG), which are both part of the Netherlands Genomics Initiative/Netherlands Organization for Scientific Research.

Conflict of interest The authors declare that they have no conflict of interest.

Open Access This article is distributed under the terms of the Creative Commons Attribution Noncommercial License which permits any noncommercial use, distribution, and reproduction in any medium, provided the original author(s) and source are credited.

\section{References}

Afzal AJ, Wood AJ, Lightfoot DA (2008) Plant receptor-like serine threonine kinases: roles in signaling and plant defense. Mol Plant Microbe Interact 21:507-517

Andrea B, Rüdiger S (2009) Interdomain signaling in stem cell maintenance of plant shoot meristems. Mol Cells 27:615-620

Birnbaum K, Shasha DE, Wang JY, Jung J, Lambert GM, Galbraith DW, Benfey PN (2003) A gene expression map of the Arabidopsis root. Science 302:1956-1960

Bommert P, Lunde C, Nardmann J, Vollbrecht E, Running M, Jackson D, Hake S, Werr S (2005) Thick tassel dwarf1 encodes a putative maize ortholog of the Arabidopsis CLAVATA1 leucine-rich repeat receptor-like kinase. Development 132:1235-1245

Bonello JF, Sevilla-Lecoq S, Berne A, Risueno MC, Dumas C, Rogowsky PM (2002) Esr proteins are secreted by the cells of the embryo surrounding region. J Exp Bot 53:1559-1568

Brand U, Fletcher JC, Hobe M, Meyerowitz EM, Simon R (2000) Dependence of stem cell fate in Arabidopsis on a feedback loop regulated by CLV3 activity. Science 289:617-619

Butenko MA, Vie AK, Brembu T, Aalen RB, Bones AM (2009) Plant peptides in signalling: looking for new partners. Trends Plant Sci $14: 255-263$

Casamitjana-Martinez E, Hofhuis HF, Xu J, Liu CM, Heidstra R, Scheres B (2003) Root-specific CLE19 overexpression and the sol1/2 suppressors implicate a CLV-like pathway in the control of Arabidopsis root meristem maintenance. Curr Biol 13:1435-1441

Chu H, Qian Q, Liang W, Yin C, Tan H, Yao X, Yuan Z, Yang J, Huang H, Luo D, Ma H, Zhang D (2006) The FLORAL ORGAN NUMBER4 gene encoding a putative ortholog of Arabidopsis CLAVATA3 regulates apical meristem size in rice. Plant Physiol 142:1039-1052

Clark SE, Running MP, Meyerowitz EM (1995) CLAVATA3 is a specific regulator of shoot and floral meristem development affecting the same processes as CLAVATA1. Development 121:2057-2067

Clark SE, Williams RW, Meyerowitz EM (1997) The CLAVATA1 gene encodes a putative receptor kinase that controls shoot and floral meristem size in Arabidopsis. Cell 89:575-585

Cock JM, McCormick S (2001) A large family of genes that share homology with CLAVATA3. Plant Physiol 126:939-942

Davis EL, Mitchum MG (2005) Nematodes, sophisticated parasites of legumes. Plant Physiol 137:182-1188

De Smet I, Vassileva V, De Rybel B, Levesque MP, Grunewald W, Van Damme D, Van Noorden G, Naudts M, Van Isterdael G, De Clerq R (2008) Receptor-like kinase ACR4 restricts formative cell divisions in the Arabidopsis root. Science 322:594-597 
De Smet I, Voss U, Jürgens G, Beeckman T (2009) Receptor-like kinases shape the plant. Nat Cell Biol 11:1166-1173

DeYoung BJ, Clark SE (2008) BAM receptors regulate stem cell specification and organ development through complex interactions with CLAVATA signalling. Genetics 180:895-904

DeYoung BJ, Bickle KL, Schrage KJ, Muskett P, Patel K, Clark SE (2006) The Clavata1-related BAM1, BAM2 and BAM3 receptor kinase-like proteins are required for meristem function in Arabidopsis. Plant J 45:1-16

Diévart A, Dalal M, Tax FE, Lacey AD, Huttly A, Li JM, Clark SE (2003) CLAVATA1 dominant-negative alleles reveal functional overlap between multiple receptor kinases that regulate meristem and organ development. Plant Cell 15:1198-1211

Fiers M, Hause G, Boutilier K, Casamitjana-Martinez E, Weijers D, Offringa R, van der Geest L, van Lookeren CM, Liu CM (2004) Mis-expression of the CLV3/ESR-like gene CLE19 in Arabidopsis leads to a consumption of root meristem. Gene 327:37-49

Fiers M, Golemiec E, Xu J, van der Geest L, Heidstra R, Stiekema W, Liu CM (2005) The 14-amino acid CLV3, CLE19 and CLE40 peptides trigger consumption of the root meristem in Arabidopsis through a CLAVATA2-dependent pathway. Plant Cell 17:25422553

Fiers M, Golemiec E, van der Schors R, van der Geest L, Li KW, Stiekema W, Liu CM (2006) The CLV3/ESR motif of CLV3 is functionally independent from the non-conserved flanking sequences. Plant Physiol 141:1284-1292

Fisher K, Turner S (2007) PXY, a receptor-like kinase essential for maintaining polarity during plant vascular-tissue development. Curr Biol 17:1061-1066

Fletcher JC, Brand U, Running MP, Simon R, Meyerowitz EM (1999) Signaling of cell fate decisions by CLAVATA3 in Arabidopsis shoot meristems. Science 283:1911-1914

Fritz-Laylin LK, Krishnamurthy N, Tör M, Sjölander KV, Jones JDG (2005) Phylogenomic analysis of the receptor-like proteins of rice and Arabidopsis. Plant Physiol 138:611-623

Gifford ML, Robertson FC, Soares DC, Ingram GC (2005) ARABIDOPSIS CRINKLY4 function, internalization, and turnover are dependent on the extracellular crinkly repeat domain. Plant Cell 17:1154-1166

Groß-Hardt R, Laux T (2003) Stem cell regulation in the shoot meristem. J Cell Sci 116:1659-1666

Hara K, Kajita R, Torii KU, Bergmann DC, Kakimoto T (2007) The secretory peptide gene EPF1 enforces the stomatal one-cellspacing rule. Genes Dev 21:1720-1725

Hirakawa Y, Shinohara H, Kondo Y, Inoue A, Nakanomyo I, Ogawa M, Sawa S, Ohashi-Ito K, Matsubayashi Y, Fukuda H (2008) Non-cell-autonomous control of vascular stem cell fate by a CLE peptide/receptor system. Proc Natl Acad Sci USA 105:1520815213

Hobe M, Muller R, Grunewald M, Brand U, Simon R (2003) Loss of CLE40, a protein functionally equivalent to the stem cell restricting signal CLV3, enhances root waving in Arabidopsis. Dev Genes Evol 213:371-381

Hord CL, Chen C, Deyoung BJ, Clark SE, Ma H (2006) The BAM1/ BAM2 receptor-like kinases are important regulators of Arabidopsis early anther development. Plant Cell 18:1667-1680

Ito Y, Nakanomyo I, Motose H, Iwamoto K, Sawa S, Dohmae N, Fukuda H (2006) Dodeca-CLE peptides as suppressors of plant stem cell differentiation. Science 313:842-845

Jeong S, Trotochaud AE, Clark SE (1999) The Arabidopsis CLAVATA2 gene encodes a receptor-like protein required for the stability of the CLAVATA1 receptor-like kinase. Plant Cell 11:1925-1933

Kayes JM, Clark SE (1998) CLAVATA2, a regulator of meristem and organ development in Arabidopsis. Development 125:38433851
Kinoshita A, Nakamura Y, Sasaki E, Kyozuka J, Fukuda H, Sawa S (2007) Gain-of-function phenotypes of chemically synthetic CLAVATA3/ESR-related (CLE) peptides in Arabidopsis thaliana and Oryza sativa. Plant Cell Physiol 48:1821-1825

Kondo T, Sawa S, Kinoshita A, Mizuno S, Kakimoto T, Fukuda H, Sakagami Y (2006) A plant peptide encoded by CLV3 identified by in situ MALDI-TOF MS analysis. Science 313:845-848

Kwak SH, Shen R, Schiefelbein J (2005) Positional signaling mediated by a receptor-like kinase in Arabidopsis. Science 307:1111-1113

Laux T, Mayer KF, Berger J, Jürgens G (1996) The WUSCHEL gene is required for shoot and floral meristem integrity in Arabidopsis. Development 122:87-96

Lenhard M, Laux T (2003) Stem cell homeostasis in the Arabidopsis shoot meristem is regulated by intercellular movement of CLAVATA3 and its sequestration by CLAVATA1. Development 130:3163-3173

Lu SW, Chen S, Wang J, Yu H, Chronis D, Mitchum MG, Wang X (2009) Structural and functional diversity of CLAVATA3/ESR (CLE)-like genes from the potato cyst nematode Globodera rostochiensis. MPMI 22:1128-1142

Mitchum MG, Wang X, Davis EL (2008) Diverse and conserved roles of CLE peptides. Curr in Plant Biol 11:75-81

Miwa H, Betsuyaku S, Iwamoto K, Kinoshita A, Fukuda H, Sawa S (2008) The receptor-like kinase SOL2 mediates CLE signaling in Arabidopsis. Plant Cell Physiol 49:1752-1757

Miwa H, Tamaki T, Fukuda H, Sawa S (2009) Evolution of CLE signaling: origins of the CLV1 and SOL2/CRN receptor diversity. Plant Signal Behav 6:477-481

Mizuno S, Osakabe Y, Maruyama K, Ito T, Osakabe K, Sato T, Shinozaki K, Yamaguchi-Shinozaki K (2007) Receptor-like protein kinase 2 (RPK 2) is a novel factor controlling anther development in Arabidopsis thaliana. Plant J 50:751-766

Müller R, Borghi L, Kwiatkowska D, Laufs P, Simon R (2006) Dynamic and compensatory responses of Arabidopsis shoot and floral meristems to CLV3 signaling. Plant Cell 18:11881198

Müller R, Bleckmann A, Simon R (2008) The receptor kinase CORYNE of Arabidopsis transmits the stem cell-limiting signal CLAVATA3 independently of CLAVATA1. Plant Cell 20:934946

Nagasawa N, Miyoshi M, Kitano H, Satoh H, Nagato Y (1996) Mutations associated with floral organ number in rice. Planta 198:627-633

Ni J, Clark SE (2006) Evidence for functional conservation, sufficiency, and proteolytic processing of the CLAVATA3 CLE domain. Plant Physiol 140:726-733

Nodine MD, Tax FE (2008) Two receptor-like kinases required together for the establishment of Arabidopsis cotyledon primordia. Dev Biol 314:161-170

Nodine MD, Yadegari R, Tax FE (2007) RPK1 and TOAD2 are two receptor-like kinases redundantly required for Arabidopsis embryonic pattern formation. Dev Cell 12:943-956

Oelkers K, Goffard N, Weiller GF, Gresshoff PM, Mathesius U, Frickey T (2008) Bioinformatics analysis of the CLE signaling peptide family. BMC Plant Biol 8:1-15

Ogawa M, Shinohara H, Sakagami Y, Matsubayashi Y (2008) Arabidopsis CLV3 peptide directly binds CLV1 ectodomain. Science 319:294

Ohyama K, Shinohara H, Ogawa-Ohnishi M, Matsubayashi Y (2009) A glycopeptide regulating stem cell fate in Arabidopsis thaliana. Nature Chem Biol 5:578-580

Olsen AN, Skriver K (2003) Ligand mimicry? Plant-parasitic nematode polypeptide with similarity to CLAVATA3. Trends Plant Sci 8:55-57 
Opsahl-Ferstad HG, Le Deunff E, Dumas C, Rogowsky PM (1997) $Z m E s r$, a novel endosperm-specific gene expressed in a restricted region around the maize embryo. Plant J 12:235-246

Osakabe Y, Maruyama K, Seki M, Satou M, Shinozaki K, YamaguchiShinozaki K (2005) Leucine-rich repeat receptor-like kinase1 is a key membrane-bound regulator of abscisic acid early signaling in Arabidopsis. Plant Cell 17:1105-1119

Reddy GV, Meyerowitz EM (2005) Stem-cell homeostasis and growth dynamics can be uncoupled in the Arabidopsis shoot apex. Science 310:663-667

Rojo E, Sharma VK, Kovaleva V, Raikhel NV, Fletcher JC (2002) CLV3 is localized to the extracellular space, where it activates the Arabidopsis CLAVATA stem cell signaling pathway. Plant Cell 14:969-977

Schoof H, Lenhard M, Haecker A, Mayer KFX, Jürgens G, Laux T (2000) The stem cell population of Arabidopsis shoot meristems is maintained by a regulatory loop between the CLAVATA and WUSCHEL genes. Cell 100:635-644

Sharma VK, Ramirez J, Fletcher JC (2003) The Arabidopsis CLV3like $(C L E)$ genes are expressed in diverse tissues and encode secreted proteins. Plant Mol Biol 51:415-425

Shiu SH, Bleecker AB (2001) Plant receptor-like kinase gene family: diversity, function, and signaling. Sci STKE 113:1-13

Shpak ED, McAbee JM, Pillitteri LJ, Torii KU (2005) Stomatal patterning and differentiation by synergistic interactions of receptor kinases. Science 309:290-293

Stahl Y, Wink RH, Ingram GC, Rüdiger S (2009) A signaling module controlling the stem cell niche in Arabidopsis root meristems. Curr Biol 19:909-914

Stein JC, Howlett B, Boyes DC, Nasrallah ME, Nasrallah JB (1991) Molecular cloning of a putative receptor protein kinase gene encoded at the self-incompatibility locus of Brassica oleracea. Proc Natl Acad Sci U S A 88:8816-8820

Strabala TJ, O’Donnell PJ, Smit AM, Ampomah-Dwamena C, Jane Martin E, Netzler N, Nieuwenhuizen NJ, Quinn BD, Foote HCC, Hudson KR (2006) Gain-of-function phenotypes of many CLAVATA3/ESR Genes, including four new family members, correlate with tandem variations in the conserved CLAVATA3/ ESR domain. Plant Physiol 140:1331-1344

Suzaki T, Sato M, Ashikari M, Miyoshi M, Nagato Y, Hirano HY (2004) The gene FLORAL ORGAN NUMBER1 regulates floral meristem size in rice and encodes a leucine-rich repeat receptor kinase orthologous to Arabidopsis CLAVATA1. Development 131:5649-5657
Suzaki T, Toriba T, Fujimoto M, Tsutsumi N, Kitano H, Hirano HY (2006) Conservation and diversification of meristem maintenance mechanism in Oryza sativa: function of the FLORAL ORGAN NUMBER2 gene. Plant Cell Physiol 47:1591-1602

Suzaki T, Yoshida A, Hirano HY (2008) Functional diversification of CLAVATA3-related CLE proteins in meristem maintenance in rice. Plant Cell 20:2049-2058

Taguchi-Shiobara F, Yuan Z, Hake S, Jackson D (2001) The fasciated ear2 gene encodes a leucine-rich repeat receptor-like protein that regulates shoot meristem proliferation in maize. Genes Dev $15: 2755-2766$

Torii KU, Mitsukawa N, Oosumi T, Matsuura Y, Yokoyama R, Whittier RF, Komeda Y (1996) The Arabidopsis ERECTA gene encodes a putative receptor protein kinase with extracellular leucine-rich repeats. Plant Cell 8:735-746

Trotochaud AE, Hao T, Wu G, Yang Z, Clark SE (1999) The CLAVATA1 receptor-like kinase requires CLAVATA3 for its assembly into a signalling complex that includes KAPP and a Rho-related protein. Plant Cell 11:393-405

van Zanten M, Snoek LB, Proveniers MCG, Peeters AJM (2009) The many functions of ERECTA. Trends Plant Sci 14:214-218

Wang X, Mitchum MG, Gao B, Li C, Diab H, Baum TJ, Hussey RS, Davis EL (2005) A parasitism gene from a plant-parasitic nematode with function similar to CLAVATA/ESR (CLE) of Arabidopsis thaliana. Mol Plant Path 6:187-191

Wang G, Ellendorff U, Kemp B, Mansfield JW, Forsyth A, Mitchell K, Bastas K, Liu CM, Woods-Tor E, Zipfel C, de Wit PJGM, Jones JDG, Mahmut T, Thomma BPHJ (2008) A genome-wide functional investigation into the roles of receptor-like proteins in Arabidopsis. Plant Physiol 147:503-517

Watanabe M, Tanaka H, Watanabe D, Machida C, Machida Y (2004) The ACR4 receptor like kinase is required for surface formation of epidermis-related tissues in Arabidopsis thaliana. Plant $\mathrm{J}$ 39:298-308

Whitford R, Fernandez A, De Groodt R, Ortega E, Hilson P (2008) Plant CLE peptides from two distinct functional classes synergistically induce division of vascular cells. Proc Natl Acad Sci U S A 105:18625-18630

Yadav RK, Girke T, Pasala S, Xie M, Reddy GV (2009) Gene expression map of the Arabidopsis shoot apical meristem stem cell niche. Proc Natl Acad Sci U S A 106:4941-4946

Yokoyama R, Takahashi T, Kato A, Torii KU, Komeda Y (1998) The Arabidopsis ERECTA gene is expressed in the shoot apical meristem and organ primordia. Plant J 15:301-310 